Van Laere, K., S. C. Franç, H. Vansteenkiste, J. Van Huylenbroeck, K. Steppe and M. C. Van LABEKE (2011): Influence of ploidy level on morphology, growth and drought susceptibility in Spathiphyllum wallisii. Acta Physiologiae Plantarum 33: 1149-1156.

Vyas, P. M., S. Bisht, S. I. Miyazawa, S. Yano, K. Noguchi, I. Terashima and S. FunayamaNoGUCHI (2007): Effects of polyploidy on photosynthetic properties and anatomy in leaves of Phlox drummondii. Funct Plant Biol 34: 673-682.

WANG, L., F. GAO, K. XU and X. Li (2014): Natural occurrence of mixoploid ginger (Zingiber officinale Rosc.) in China and its morphological variations. Sciencia Horticulturae 172: 54-60.

WARNER, D. A. and G. E. EDWARDS (1993): Effects of Polyploidy on Photosynthesis. Photosynthesis Research 35: 135-147.

Webb, W. L., M. Newton and D. Starr (1974): Carbon dioxide exchange of Alnus rubra - a mathematical model. Oecologia 17: 281-291.

XU, L. and D. BALDOCCHI (2003): Seasonal trends in photosynthetic parameters and stomatal conduc- tance of blue oak (Quercus douglasii) under prolonged summer drought and high temperature. Tree Physiology 23: 865-877.

Xu, C., T. Tang, R. Chen, C. Liang, X. LiU, C. WU, Y. YANG, D. YANG and H. WU (2014): A comparative study of bioactive metabolite production in diploid and tetraploid Echinea purpurea (L.) Moench. Plant Cell Tiss Organ Cult 116: 323-332.

Zhang, L. M., G. Yu, X. Sun, X. Wen, C. Ren, Y. Fu, Q. LI, Z. LI, Y. LIU, D. GUAN and J. YAN (2006): Seasonal variations of ecosystem apparent quantum yield $(\alpha)$ and maximum photosynthesis rate $\left(\mathrm{P}_{\max }\right)$ of different forest ecosystems in China. Agric For Meteorol 137: 176-187.

Zsuffa, L., E. Giondano, L. D. Pryor and R. F. STETTLER (1996): Trends in poplar culture: some global and regional perspectives, pp. 515-539. In: Biology of Populus and its Implications for Management and Conservation, Part II, edited by R. F. Stettler, H. D. Bradshaw JR., P. E. Heilman and T. M. Hinckley. NRC Research Press, National Research Council of Canada, Ottawa.

\title{
Estimation of genetic parameters for height using spatial analysis in Tsuga heterophylla full-sibling family trials in British Columbia
}

\author{
By E. P. CAPPA ${ }^{1,2), 3), *)}$, A. D. YANCHUK ${ }^{2)}$ and C. V. CARTwRIGHT ${ }^{2)}$
}

(Received 15 ${ }^{\text {th }}$ August 2014)

\begin{abstract}
Non-spatial and spatial analyses were carried out to study the effects on genetic parameters in ten-year height growth data across two series of 10 large second-generation full-sib progeny tri-

\footnotetext{
1) Department of Forest Sciences, 2424 Main Mall, University of British Columbia, Vancouver, British Columbia, V6T 1Z4, Canada.

2) British Columbia Ministry of Forests and Range, Research Branch, PO Box 9519 Stn Prov Govt, Victoria, British Columbia, V8W 9C2 Canada.

$\left.{ }^{3}\right)$ Permanent address: Instituto Nacional de Tecnología Agropecuaria (INTA), Instituto de Recursos Biológicos, De Los Reseros y Dr. Nicolás Repetto s/n, 1686, Hurlingham, Buenos Aires, Argentina - Consejo Nacional de Investigaciones Científicas y Técnicas (CONICET), Argentina.
}

als of western hemlock [Tsuga heterophylla (Raf.) Sarg.] in British Columbia. To account for different and complex patterns of environmental heterogeneity, spatial single trial analyses were conducted using an individual-tree mixed model with a two-dimensional smoothing surface with tensor product of B-spline bases. The spatial single trial analysis, in all cases, showed sizeable lower Deviance Information Criterion values relative to the non-spatial analysis. Also,

\footnotetext{
*) Corresponding author: EdUardo Pablo CAPPA. Bosques Cultivados, Instituto de Recursos Biológicos, Centro de Investigación en Recursos Naturales, Instituto Nacional de Tecnología Agropecuaria, De Los Reseros y Dr. Nicolás Repetto s/n, 1686 Hurlingham, Buenos Aires, Argentina. Phone/Fax: +54 1146210433. E-Mail: cappa.eduardo@inta.gob.ar
} 
fitting a surface displayed a consistent reduction in the posterior mean as well as a decrease in the standard deviations of error variance, no appreciable changes in the additive variance, an increase of individual narrow-sense heritability, and accuracy of breeding values. The tensor product of cubic basis functions of Bspline based on a mixed model framework does provide a useful new alternative to model different and complex patterns of spatial variability within sites in forest genetic trials. Individual narrow-sense heritabilities estimates from the spatial single trial analyses were low (average of 0.06), but typical of this species. Estimated dominance relative to additive variances were unstable across sites (from 0.00 to 1.59). The implications of these estimations will be discussed with respect to the western hemlock genetic improvement program in British Columbia.

Key words: Tsuga heterophylla, non-spatial and spatial single trial analysis, model comparison, spatial multi-environment trial analyses, B-spline, Additive and Dominance variances, Heritability, Genotype by environmental interactions.

\section{Introduction}

Western hemlock [Tsuga heterophylla (Raf.) Sarg.] is one of the most important coniferous species in the British Columbia (BC) accounting for about $60 \%$ of the of the province's coastal timber profile (WEBBER, 2000). Due to its shade tolerant growth habit it forms dense, productive stands with annual mean increment ranging as high as $17 \mathrm{~m}^{3} \mathrm{ha}^{-1}$ years $^{-1}$ (POJAR and MACKINNON, 1994) on well drained organic soils from tide water to $1100 \mathrm{~m}$ elevation. Although Douglas-fir [Pseudotsuga menziesii (Mirb) Franco] is preferred for lumber due to slightly greater wood density, strength, and resistance to decay, western hemlock is preferred for pulp based on lack of coloured extractives, and finer fibers. Western hemlock is a fecund species, amenable to both natural regeneration, and tree improvement, being a relatively easily managed seed orchard species (WEBBER, 2000).

Knowledge of genetic parameters is required to formulate breeding strategies, as well as estimated breeding values and gains from selection (WHITE, 1996). Moreover, multi-environment trials (MET) allow the study of the differential response of genotypes to different environmental conditions, i.e. quantifying the magnitude of the genotype by environment interactions if related material is tested. However, information on (co)variance genetic parameters (and functions of them) in western hemlock is extremely limited and published reports are based on only in open-pollinated families (FOSTER and LESTER, 1983; Pollard and Portlock, 1986; KING, 1990).

To ignore spatial variability in forest genetic trials leads to bias in estimating genetic parameters and predicting breeding values (MAGNUSSEN, 1993, 1994), so that accuracy of selection decreases, thus reducing genetic gain. The presence of spatial environmental patterns within most field test sites is typically influenced by factors such as variations in soil fertility, moisture content and depth, slope, and all are well known characteristics of forest genetic trials in the field (e.g., DutKowski et al., 2006; ZAS, 2006; CAPPA and CANTET, 2007; YE and JAYAWICKRAMA, 2008). To reduce the impact this environmental variability on quantitative genetic parameters tree breeders use spatial models. Spatial models permit modeling site heterogeneity by including two main components: a) 'local trend' or small-scale variation, and b) 'global trend' or large-scale variation (GRONDANA et al., 1996). The two sources are observable in forest genetic trials: either each component alone or in combination with each other (e.g., Fu et al., 1999; CosTa E SILVA et al., 2001; HAMANN et al., 2002; DUTKOWSKI et al., 2006; YE and JAYAWICKRAMA, 2008). Numerous a posteriori spatial methods have been proposed and implemented in forest genetic trials to model the small- and/or large-scale spatial variability. CAPPA and CANTET (2007) proposed to use tensor products of cubic B-splines based on a mixed model framework by treating the Bspline function parameters as random variables (i.e., using a covariance structure for the random knots effects) in a two-dimensional grid (RUPPERT et al., 2003). They illustrated the methodology to account for large-scale continuous spatial variation in an individual-tree mixed model with data from a progeny trial of Eucalyptus globulus ssp. globulus Labill. The new two-dimensional surface provided an increase in the heritability and the accuracy of the estimated breeding value of parent and offspring. However, CAPPA and CANTET (2007) did not confirm the ability of this new approach to remove complex patterns of spatial variation. CAPPA et al. (2012) extended the methodology for spatial analyses at a single forest genetic 
trial proposed by CAPPA and CANTET (2007) to a MET setting, using an individual-tree model with additive and full-sib family genetic effects in a two-stage approach. They illustrated the developments with ten-year height growth data from two series of eight large second-generation full-sib progeny trials of western hemlock established across eight sites of the North American Pacific coast. However, their work was based in the methodological aspect of this novel approach, and thus, a discussion of the genetic parameters estimated across sites for this second-generation western hemlock full-sib family trials was not reported by CAPPA et al. (2012). Additionally, their conclusions were based only on eight of the ten trials established across the North American Pacific coast.

As part of the Hemlock Tree Improvement Cooperative (HEMTIC) testing program, a number of second-generation full-sib progeny trials of western hemlock have been established across a range of sites from Washington state (United States) to the northern end of the Vancouver Island in British Columbia (BC, Canada), between 1997 and 1999. The progeny of these second-generation trials was formed by recombining the top 150 first-generation parents with two different mating designs (JAYAWICKRAMA, 2003). The goals of this research are: 1 ) to study the performance of the spatial analyses using a two-dimensional smoothing surface with tensor product of B-spline bases (CAPPA and CANTET, 2007) for different and complex patterns of spatial variation; 2 ) to study the effect of the single trial spatial analysis on estimates of genetic parameters including additive, family, and error variances, and functions of these estimates for each sites in these second-generation full-sib progeny trials of western hemlock; and 3) to compare these estimates with those derived from previous studies. Additionally, the estimates from single site spatial analysis and those estimated by CAPPA et al. (2012) using a novel spatial MET analysis, will be used to discuss the implications for genetic tree improvement of western hemlock in British Columbia.

\section{Material and Methods}

\section{Genetic material, mating design and trial description}

Forest genetics programs with western hemlock [Tsuga heterophylla (Raf.) Sarg.] in British
Columbia (BC) commenced with selections of the first parent trees at the University of British Columbia campus in the late 1950's. The first seed orchards were grafted in the next decade and the first progeny test was established in 1972. Starting in 1979, several series of open-pollinated trials were out-planted by the BC Forest Service, but due to a reduced interest in planting hemlock in the early 1980's most activities with hemlock genetic improvement ceased, and only $140 \mathrm{BC}$ parents made it into tests. The early 1990's saw a renewed interest in planting improved hemlock, and additional 170 parents were tested in open-pollinated first generation trials. It was also then that the HEMTIC emerged, with various agencies in the American Pacific Northwest. HEMTIC provided for sharing access to the more than 2000 tested parents of the region (JAYAWICKRAMA, 2003). From this initiative, second-generation breeding populations were established, and 10 of the full-sibling progeny trials used here for the single site analyses. Table 1 provides general information about the 10 field tests examined. The western hemlock full-sib second-generation program are composed of 38,948 progeny, from 483 full-sib families originating from 149 unrelated first generation selected parents, in two 'series' with two different mating structures: 1) 'Local Diallel' series (LD), composed of five six-parent disconnected partial (half) diallels representing each of five geographic programs, Oregon (2), Washington (2) and British Columbia (1), and 2) 'Elites' series (E) being composed of the 'best' 30 parents (i.e., 6 best parents from each of the five programs as ranked at the end of first generation open-pollinated tests). Each parent in the $\mathrm{E}$ series was crossed with two unrelated parents from each of the five programs. A detailed description of the genetic material included in these trials can be found in CAPPA et al. (2012). Additionally, two standard seedlots occur on all 10 sites but one (Russell). These standard seedlots were excluded for the estimation of genetic parameters. The first is a 'woods run' standard composed of 15 commercially collected seedlots from across the seed zone of interest. The second is an advanced generation standard for HEMTIC. It is a seedlot with contributions from a mix of six full-sib crosses from the most central program in the co-operative (Gray's Harbour) selected to represent the range of parental breeding values in that group. 
Table 1. - Location, sites characteristics, design information, mean with standard deviation, minimum and maximum values for Total Height at age of 10 years for each of the ten trials.

\begin{tabular}{|c|c|c|c|c|c|c|c|c|c|c|}
\hline \multirow{3}{*}{$\begin{array}{c}\text { Site } \\
\text { Latitude } \\
\text { [north) }\end{array}$} & \multirow[b]{2}{*}{ Jordan 2} & \multicolumn{5}{|c|}{ Local Diallels } & \multicolumn{4}{|c|}{ Elite Diallels } \\
\hline & & Kiyu & Jordan 3 & Rupert 1 & Russell & Humptulips & Klanawa & Stove & Tlupana & Michelsen \\
\hline & $48^{\circ} 2 b^{\prime} 16^{\prime \prime}$ & $5000507^{\prime \prime}$ & $48^{\circ} 24^{\prime} 44^{\prime \prime}$ & $50^{\prime \prime} 34^{\prime} 21^{\prime \prime}$ & $59^{\circ} 19^{\prime} 23^{\prime \prime}$ & $47^{\circ} 13^{\prime} \mathrm{b} 2^{\prime \prime}$ & $48^{\circ} 48^{\prime} 42^{\prime \prime}$ & $50^{\circ} 15^{\prime} 49^{\prime \prime}$ & $49^{\circ} 45^{\prime} 33^{\prime \prime}$ & $50^{\circ} 34^{\prime} 42^{\prime \prime}$ \\
\hline $\begin{array}{l}\text { Longitude } \\
\text { (west) }\end{array}$ & $124^{\circ} 00^{\prime} 43^{\prime \prime}$ & $126^{\circ} 30^{\prime} 00^{\prime \prime}$ & $123^{\circ} 59^{\prime} 28^{\prime \prime}$ & $127^{\circ} 23^{\prime} 44^{\prime \prime}$ & $126^{\circ} 22^{\prime} 33^{\prime \prime}$ & $123^{\circ} 54^{\prime} 15^{\prime \prime}$ & $124^{\circ} 47^{\prime} 45^{\prime \prime}$ & $125^{\circ} 40^{\prime} 02^{\prime \prime}$ & $126^{\circ} 23^{\prime} 22^{\prime \prime}$ & $127^{\circ} 41^{\prime} 30^{\prime \prime}$ \\
\hline Altitude (m) & 110 & 380 & 130 & 110 & 590 & 100 & 110 & 90 & 45 & 100 \\
\hline $\begin{array}{c}\text { Soil } \\
\text { description }\end{array}$ & $\begin{array}{l}\text { Well drained } \\
\text { moderately } \\
\text { deep, finer } \\
\text { textured podzol } \\
\text { with limited } \\
\text { litter and } \\
\text { moder organic } \\
\text { layers. }\end{array}$ & $\begin{array}{c}\text { Thin silty soils } \\
\text { over rock with } \\
2 \text { hyeric areas, } \\
\text { generallyvery } \\
\text { well drained } \\
\text { submessic } \\
\text { mesotrophic } \\
\text { site. }\end{array}$ & $\begin{array}{l}\text { Moderately } \\
\text { deep coarser } \\
\text { soils with } \\
\text { limited litter } \\
\text { and moder } \\
\text { urganic lavers, } \\
\text { well drained } \\
\text { but fairly } \\
\text { nutrient rich. }\end{array}$ & $\begin{array}{l}\text { Hummocky silty } \\
\text { soils with } \\
\text { moderately } \\
\text { decp litter and } \\
\text { organic soil } \\
\text { layers, } \\
\text { moderately } \\
\text { wcll drained } \\
\text { and fairly rich. }\end{array}$ & $\begin{array}{l}\text { Thin } \\
\text { organic } \\
\text { and silty } \\
\text { layers over } \\
\text { a hardpan } \\
\text { are poorly } \\
\text { drained } \\
\text { and } \\
\text { nutrient } \\
\text { poor. }\end{array}$ & $\begin{array}{c}\text { Deeper, silty } \\
\text { soils with } \\
\text { limited organic } \\
\text { layers, for mast } \\
\text { of the area well } \\
\text { drained mesic } \\
\text { and fairly rich. } \\
\text { In bottom of the } \\
\text { slope } \\
\text { permanent high } \\
\text { watnr table. }\end{array}$ & $\begin{array}{l}\text { Limitrd } \\
\text { organic } \\
\text { matter over } \\
\text { thin, well } \\
\text { drained silty } \\
\text { mesotraphic } \\
\text { soil covers } \\
\text { rock. }\end{array}$ & $\begin{array}{l}\text { Moderately } \\
\text { deep silt soils } \\
\text { with a moder } \\
\text { form orgainic } \\
\text { layer, generally } \\
\text { well drained } \\
\text { except in two } \\
\text { areas. }\end{array}$ & $\begin{array}{l}\text { Moderately } \\
\text { deep silty soils } \\
\text { with thin litter } \\
\text { and organic } \\
\text { layers that are } \\
\text { generally well } \\
\text { drained, except } \\
\text { in some areas. }\end{array}$ & $\begin{array}{l}\text { Most of the } \\
\text { area is a } \\
\text { subhygric, } \\
\text { eutrophic } \\
\text { podzol with a } \\
\text { moderately } \\
\text { deep orgarlic } \\
\text { layer but with a } \\
\text { couple arcas of } \\
\text { high water } \\
\text { table? }\end{array}$ \\
\hline $\operatorname{AMT}^{\mathrm{b}}\left({ }^{\prime} \mathrm{C}\right)$ & 9.2 & 7.9 & 9.3 & 8.2 & 6.4 & 10.3 & 9.6 & 8.4 & 8.9 & 8.4 \\
\hline $\begin{array}{l}\text { MTсM }{ }^{\mathrm{C}}\left\{{ }^{ } \mathrm{C}\right) / \\
\operatorname{MTWM}^{\mathrm{d}}\left({ }^{\circ} \mathrm{C}\right)\end{array}$ & $0.4 / 70.9$ & $-1.7 / 77.1$ & $0.5 / 71$ & $0 / 19.5$ & $-0.7 / 14.5$ & $1.5 / 71.9$ & $3.6 / 16.3$ & $-1.4 / 21.1$ & $0.3 / 21.6$ & $0.4 / 19.7$ \\
\hline $\begin{array}{l}\text { Number of } \\
\text { Initial Trees }\end{array}$ & 7680 & 7680 & 8320 & 7188 & 3200 & 8320 & 1610 & 4800 & 4800 & 4800 \\
\hline $\begin{array}{l}\text { Number of } \\
\text { Parents }\end{array}$ & 138 & 138 & 149 & 149 & 137 & 149 & 30 & 30 & 30 & 30 \\
\hline $\begin{array}{l}\text { Nurnber of } \\
\text { Families }\end{array}$ & 324 & 314 & 342 & 342 & 249 & 339 & 132 & 141 & 137 & 140 \\
\hline $\begin{array}{l}\text { Number of } \\
\text { Check Lots } \\
\text { Number of }\end{array}$ & 2 & 2 & 2 & 2 & 0 & 2 & 2 & 2 & 2 & 2 \\
\hline $\begin{array}{l}\text { Trees with } \\
\text { Records }\end{array}$ & د30 & 3830 & 4393 & 4384 & 1870 & $5, E 1$ & 2931 & 3660 & 3428 & 3582 \\
\hline Field design ${ }^{c}$ & 5 in $R$ & $\sin R$ & $S$ i r $R$ & $\sin R$ & $S$ in $R$ & $\operatorname{Sin} R$ & I $\underline{E B}$ & ICB & ICB & $\mathrm{ICB}$ \\
\hline Replicates & 20 & 20 & 20 & 18 & 10 & 20 & 29 & 30 & 30 & 30 \\
\hline Columns & 104 & 88 & 199 & 143 & 100 & 144 & 96 & 186 & 96 & 149 \\
\hline Spacing (m) & $2 \times 2$ & $2.5 \times 2.5$ & $3 \times 2.5$ & $2.5 \times 2.5$ & $2.5 \times 2.5$ & $2 \times 2$ & $2.5 \times 2.5$ & $2.5 \times 2.5$ & $2.5 \times 2.5$ & $2.5 \times 2.5$ \\
\hline $\begin{array}{c}\text { Mean } \\
(\mathrm{cm})(\mathrm{SD})\end{array}$ & $\begin{array}{c}548.8 \\
(150.1)\end{array}$ & $\begin{array}{c}488.8 \\
(151.2)\end{array}$ & $\begin{array}{c}699.6 \\
\{148.0\}\end{array}$ & $\begin{array}{c}648.5 \\
(175.8)\end{array}$ & $\begin{array}{c}549.6 \\
(120.7)\end{array}$ & $\begin{array}{c}606.5 \\
(159.7)\end{array}$ & $\begin{array}{c}610.57 \\
\{160.50\}\end{array}$ & $\begin{array}{c}632.9 \\
(141.5)\end{array}$ & $\begin{array}{c}604.1 \\
(162.1\}\end{array}$ & $\begin{array}{c}697.1 \\
(134.5)\end{array}$ \\
\hline
\end{tabular}

Note: ${ }^{\mathrm{a}} \mathrm{AMP}$ : annual mean precipitation; ${ }^{\mathrm{b}} \mathrm{AMT}$ : annual mean temperature; ${ }^{\mathrm{c}} \mathrm{MTCT}$ : minimum mean temperature of the coldest month (usually January); ${ }^{d}$ MTWM: maximum mean temperature of the warmest month (usually August); ${ }^{\text {e }} \mathrm{S}$ in R: 'Sets in Replicates' design; ICB: Incomplete block design (Alpha design); ${ }^{\text {S }} \mathrm{SD}$ : standard deviation.

The six trials of the LD series were established in a 'Sets in Replicates' design (SCHUTZ and Cockerham, 1966; 'S in R'), with families within a local diallel grouped together in a set ('genetic group'). Each replicate include all the sets. Preliminary single-site analyses showed that genetic groups (i.e., sets) were statistically differences $(p<0.05)$ in the six trials analyzed of the LD series. The families of the four trials of the $\mathrm{E}$ series were planted in incomplete block alpha design (Williams and Metheson, 1994; IB) with 30 replications and 10 incomplete blocks within replications. Single tree plots were used in all trials. Tree spacing was
$2 \times 2 \mathrm{~m}, 2.5 \times 2.5 \mathrm{~m}$ or $3 \times 2.5 \mathrm{~m}$, depending upon land availability. The trait analyzed was total height $(\mathrm{HT}, \mathrm{cm})$ measured at age 10 . The six LD series trials were planted in 1997 and 1998 and the four ED series sites were planted in 1999. They are distributed along the Pacific coast, from Washington State to the northern end of the Vancouver Island in BC (i.e. from $47^{\circ} 13$ ' 52 " to $50^{\circ} 34^{\prime} 42^{\prime \prime}$ of latitude north, from $123^{\circ} 54^{\prime} 15^{\prime \prime}$ to $127^{\circ} 41^{\prime} 30^{\prime \prime}$ of longitude west and from 45 to 590 meters of altitude). Eight of these ten HEMITIC full-sib progeny trials, five from the LD series (Jordan 2, Kiyu, Jordan 3, Rupert 1 and Humptulips) and three from the 
ED series (Stove, Tlupana and Michelsen) were used by CAPPA et al. (2012) for the two-stage spatial MET analysis.

\section{Statistical models of analysis}

Four individual-tree mixed models were evaluated on each site: one non-spatial (NonSP) and three spatial (SP) models. In matrix notation, the non-spatial individual-tree mixed models with additive and specific full-sib family genetic effects of a general form for the LD and E series is:

$$
\boldsymbol{y}=X \boldsymbol{\beta}+Z_{a} a+Z_{f} f+e
$$

where the vector $\boldsymbol{y}$ contains the phenotypic data for each site; the vector $\boldsymbol{\beta}$ included the fixed effects of genetic groups (i.e., from 23 to 26; $\mathrm{LD}$ series) and overall site mean (E series); $\boldsymbol{a}$ is the vector of random additive genetic effects of individual trees (breeding values); $\boldsymbol{f}$ is the vector of random specific full-sib family genetic effects (specific combining ability effects) and e is the vector of random error; $\boldsymbol{X}, \boldsymbol{Z}_{a}$ and $\boldsymbol{Z}_{f}$ are incidence matrices relating the observations $(\boldsymbol{y})$ to the model effects $\boldsymbol{\beta}, \boldsymbol{a}$ and $\boldsymbol{f}$, respectively. The vector a was assumed distributed as $N \sim(\boldsymbol{O}, \boldsymbol{A}$ $\sigma_{a}^{2}$ ) where $\boldsymbol{A}$ is the additive tree-level relationship matrix (HENDERSON, 1984) for the trial trees and their known ancestors, and $\sigma_{a}^{2}$ is the additive genetic variance. A Gaussian density is also assumed for full-sib family effects $\boldsymbol{f} \sim N(\boldsymbol{O}, \boldsymbol{I}$ $\sigma_{f}^{2}$ ) where $\boldsymbol{I}$ is a identity matrix and $\sigma_{f}^{2}$ is the full-sib family variance, which includes one quarter of the dominance genetic variance $\left(\sigma_{d}^{2}\right)$. Finally, the vector $\boldsymbol{e}$ is distributed as $\boldsymbol{e} \sim N(\boldsymbol{0}, \boldsymbol{I}$ $\sigma_{e}^{2}$ ) and $\sigma_{e}^{2}$ is the error variance. Additionally, the non-spatial model [1], include replicate effects [vector $\boldsymbol{r} \sim N\left(\boldsymbol{0}, \boldsymbol{I} \sigma_{r}^{2}\right), \mathrm{LD}$ series] and incomplete block effects [vector $\boldsymbol{s} \sim N\left(\boldsymbol{O}, \boldsymbol{I} \boldsymbol{\sigma}_{s}^{2}\right)$, E series] as random design effects.

A smoothing surface with different number of knots: $10 \times 10 \quad($ SP10), $20 \times 20 \quad($ SP20) and $30 \times 30$ (SP30) was added to model [1] following CAPPA and CANTET (2007) closely. Then, an individual-tree mixed model with additive and specific full-sib family genetic effects that include a smoothed surface to account for environmental heterogeneity is equal to

$$
\boldsymbol{y}=\boldsymbol{X} \boldsymbol{\beta}+\boldsymbol{B} \boldsymbol{b}+\boldsymbol{Z}_{a} \boldsymbol{a}+\boldsymbol{Z}_{f} \boldsymbol{f}+\boldsymbol{e}
$$

where $\boldsymbol{B}$ has dimension $n \times\left(n x_{r}=\right.$ number of knots for rows $\times n x_{c}=$ number of knots for columns $)$ and is equal to $\boldsymbol{B}=\left(\boldsymbol{B}_{r} \otimes 1^{\prime}{ }_{n x_{c}}\right) \#$ $\left(1_{n x_{r}}^{\prime} \otimes \boldsymbol{B}_{c}\right), \boldsymbol{B}_{i}(i=r$ or $c)$ are the matrices of the order $n \times n x_{i}$ that contains the $d+1$ nonzero Bspline bases needed to express each row and column in terms of cubic B-spline bases. Calculations of the $\boldsymbol{B}_{i}(i=r$ or $c$ ) coefficients were performed using the recursive algorithm of $\mathrm{DE}$ Boor (1993). The symbols $\otimes$ and \# indicate the Kronecker and Hadamard products of matrices, respectively (HARVILLE, 1997). The parametric vector $\boldsymbol{b}$ of order $\left(n x_{r} \times n x_{c}\right) \times 1$ contains the parameters of the tensorial product of Bsplines. The distribution of the random vector $\boldsymbol{b}$ is such that $\boldsymbol{b} \sim N\left(\boldsymbol{O}, \boldsymbol{U} \sigma_{b}^{2}\right)$. The scalar $\sigma_{b}^{2}$ is the variance of the random knot effects (RKE, CAPPA and CANTET, 2007) for rows and columns and $\boldsymbol{U}$ of order $\left(n x_{r} \times n x_{c}\right) \times\left(n x_{r} \times n x_{c}\right)$ is the covariance structure in two dimensions for the B-spline knots. In the present study, and following to CAPPA and CANTET (2007), we select as covariance structure the simple tridiagonal matrix originally proposed by GREEN and SilvERMAN (1994, p. 13) and then used by DURBAN et al. (2001) to fit a fertility trend. However, there are other dense structures that allow modeling a gradual decay in correlation as knots are separated further in the direction of the rows or of the columns, such as those proposed by Cantet et al. (2005) or HYNDMAN et al. (2005). A more detailed explanation of the twodimensional surface $(\boldsymbol{B} \boldsymbol{b})$ using the tensor product of cubic B-splines with equal number of knots for row and column, can be found in CAPPA and CANTET (2007, pp. 2678-2679).

\section{Spatial analysis of residuals}

In order to identify spatial patterns of site heterogeneity in the data of each site, we examined the spatial distribution of the residuals of tree HT, using a model with fixed effects of genetic groups (LD series) and overall mean (E series) and random effect of breeding values and full-sibs family effects (LD and E). As expected, different spatial patterns of site heterogeneity were observed among the 10 trials; i.e., a) small-scale variation (Kiyu, Jordan 3, Klanawa and Russell), b) large-scale variation in one dimension either across rows (Humptulips and Michelsen) or columns (Jordan 2 and Stove) combined with small-scale variation; and c) large-scale variation in two dimensions (i.e., across rows and columns; Rupert 1 and Tuplana) combined with small-scale variation. Three examples of these types of spatial distri- 
a)
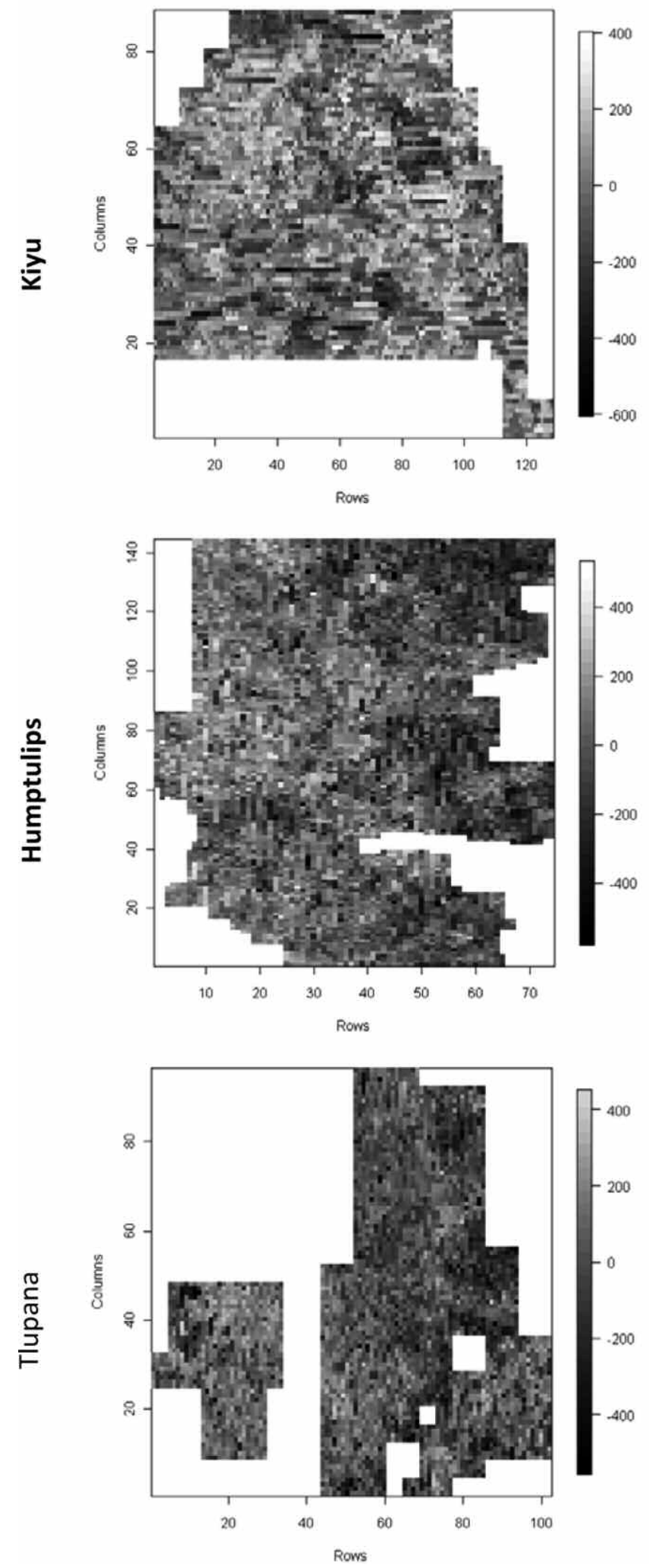

b)
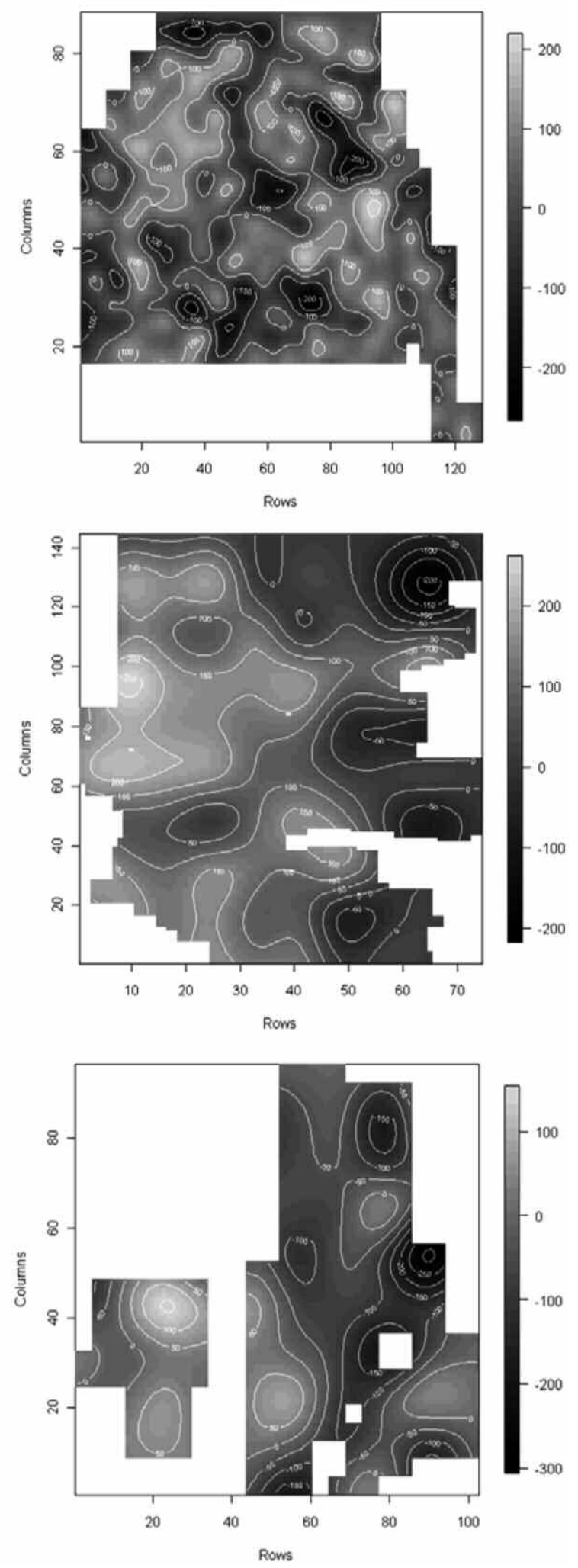

Figure 1. - First column: a) typical spatial patterns of the residuals of tree HT found on three of the 10 western hemlock progeny trials; one exhibiting small-scale variation (Kiyu), one exhibiting distinct large-scale variation in one dimension together with small-scale variation (Humptulips), and one exhibiting distinct large-scale variation in two dimension together with small-scale variation (Tlupana). Intensity of the shading of the squares represent the magnitude of the residuals; the darker the square, the larger the residual (empty square areas represent no planted tree). Second column: b) best surfaces (i.e., smaller DIC) from the fitting of tensor product B-splines with either 30 (Kiyu) and 10 (Humptulips and Tlupana) knots. 
butions of HT residuals are in Figure 1a. The color intensity represents the magnitude of the residuals. Note that the residuals are not randomly distributed in the three experimental fields.

\section{Bayesian inference and model comparison}

The Bayesian approach via Gibbs sampling was used to estimate the parameters in the non-spatial model [1] and spatial single trial models [2] following to CAPPA and CANTET (2007). Conjugate prior densities were chosen for all parameters. The assumed prior distribution of the parameter for the models [1] and [2] are: $\boldsymbol{\beta} \sim N(\boldsymbol{O}, \boldsymbol{K})$ with $\boldsymbol{K}$ a diagonal matrix with large elements $\left(k_{i i}>10^{8}\right), \boldsymbol{r} \sim N\left(0, \boldsymbol{I} \sigma_{r}^{2}\right), \boldsymbol{s} \sim N(0$, $\left.\boldsymbol{I} \sigma_{s}^{2}\right), \boldsymbol{b} \sim N\left(0, \boldsymbol{U} \sigma_{b}^{2}\right), \boldsymbol{a} \sim N\left(0, \boldsymbol{A} \sigma_{a}^{2}\right), \boldsymbol{f} \sim N(0, \boldsymbol{I}$ $\left.\sigma_{f}^{2}\right), \sigma_{i}^{2} \sim \operatorname{Inv}-\chi^{2}\left(\delta_{i}^{2}, v_{i}\right)$ with $i=\boldsymbol{r}, \boldsymbol{s}, \boldsymbol{b}, \boldsymbol{a}, \boldsymbol{f}$ and $\boldsymbol{e}$. In these expressions, $N$ is the Gaussian distribution, Inv- $\chi^{2}$ is the Scaled inverted Chisquare distribution with hypervariances $\delta_{i}^{2}$ and degrees of belief $v_{i}$, for $i=\boldsymbol{r}, \boldsymbol{s}, \boldsymbol{b}, \boldsymbol{a}, \boldsymbol{f}$ and $\boldsymbol{e}$, respectively. Therefore, the joint and conditional posterior densities are Gaussian for $\boldsymbol{r}, \boldsymbol{s}$, $\boldsymbol{b}, \boldsymbol{a}, \boldsymbol{f}$ and $\boldsymbol{e}$, and Scaled inverted Chi-square for the $\sigma_{i}^{2}$.

The values of the hypervariances $\delta_{i}^{2}$ with $i=\boldsymbol{r}$, $\boldsymbol{s}, \boldsymbol{b}, \boldsymbol{a}, \boldsymbol{f}$ and $\boldsymbol{e}$, were estimated from the same raw phenotypic data set using an empirical Bayes approach via Gibbs sampling, with an individual-tree model including fixed effects of blocks and genetic groups, and random additive and full-sib family genetic effects. As there was no prior information on the hypervariance of the RKE, we tried different values of $\delta_{b}^{2}$ in the interval $\left[0, \delta_{e}^{2}\right)$ and found that the algorithm converged always to the same posterior mean of $\sigma_{b}^{2}$ in all spatial models. In all cases, the degrees of belief were then set to 10 (i.e. $v_{i}=n_{A}$ $=10)$ to reflect a relatively high degree of uncertainty (SoRENSEN and Gianola, 2002; page 57).

For each non-spatial and spatial single trial models, a single long Gibbs chain of 1,010,000 samples was drawn, and the first 10,000 iterates were discarded as 'burn-in'. The 1,000,000 additional samples were used for computing the summary from the marginal posterior distribution in each model. Convergence was monitored by plotting the iterations against the mean of the draws up to each iteration (running mean plots) for each parameter. Marginal posterior densities for all parameters were estimated by the Gaussian kernel method (SILvERMAN 1986, chap. 2). Means, modes, medians, standard deviations, and $95 \%$ high posterior density intervals (95\% HPD), were then calculated using "Bayesian Output Analysis" (BOA version 1.0.1; SMITH, 2003) for all parameters from the individual marginal posteriors, using software R (R Development Core Team 2011).

At the end of each iteration of the Gibbs sampling individual narrow-sense heritability $\left(\hat{h}_{\mathrm{N}}^{2}\right)$, dominance variance $\left(\sigma_{d}^{2}\right)$ and individual broadsense heritability $\left(\hat{h}_{\mathrm{B}}^{2}\right)$ was calculated for each single trial as follows:

$$
\hat{h}_{\mathrm{N}}^{2}=\frac{\hat{\sigma}_{\alpha}^{2}}{\hat{\sigma}_{\alpha}^{2}+\hat{\sigma}_{f}^{2}+\hat{\sigma}_{e}^{2}} ; \quad \hat{\sigma}_{d}^{2}=4 \times \hat{\sigma}_{f}^{2} ; \quad \hat{h}_{\mathrm{B}}^{2}=\frac{\hat{\sigma}_{\alpha}^{2}+\hat{\sigma}_{d}^{2}}{\hat{\sigma}_{\alpha}^{2}+\hat{\sigma}_{f}^{2}+\hat{\sigma}_{e}^{2}}
$$

where, $\hat{\sigma}_{a}^{2}, \hat{\sigma}_{f}^{2}$, and $\hat{\sigma}_{e}^{2}$ are the values of the additive, full-sib family genetic, and error variances sampled at a given iteration.

The Deviance Information Criterion (DIC, SPIEgelHalter et al., 2002) was computed to compare the fit of each single trial model. The DIC criterion is defined as: DIC $=\bar{D}\left(\boldsymbol{\theta}_{M}\right)+p_{D}$, where $\bar{D}\left(\boldsymbol{\theta}_{M}\right)$ is the posterior mean of the deviance and $p_{D}$ the 'effective number of parameters'. A smaller DIC value indicates a better fit and lower degree of model complexity. Additional model comparisons were provided by a visual inspection of the spatial patterns of the residuals and the resulting estimates surfaces. Finally, the accuracy of predicted breeding values (acc) was computed using the following expression:

$$
\boldsymbol{a c c}=\sqrt{\frac{1-\mathrm{PEV}}{\hat{\sigma}_{a}^{2}}}
$$

where PEV stands for 'prediction error variance' (HENDERSON, 1984) of predicted breeding values using the 'Best Linear Unbiased Predictors' (BLUP's) of parent and offspring. Estimates of the additive genetic variance were those obtained in each of the non-spatial and spatial models. Spearman-rank correlations using PROC CORR of SAS were also calculated to compare whether the ranking of predicted breeding values differed between the non-spatial individual-tree model and the best individual-tree model with a two-dimensional surface. Relative genetic gains were predicted from each model as the posterior means of the breeding values for the top $20 \%$ of parents and the best $5 \%$ for offspring (Costa e Silva et al., 2001). 
Computer programs employed to carry out the Bayesian inference, as well as to solve the mixed models equations and to obtain corresponding accuracies of all models analyses were developed in FORTRAN (the FORTRAN program is available upon request).

\section{Results and Discussion}

\section{Model comparison}

It has been reported that a posteriori spatial model yields a more efficient analysis than the classical a priori design models when the spatial structure is pronounced in forest genetic trials (e.g. Costa e Silva et al., 2001; SAEnZROMERo, 2001; JoYCE et al., 2002; DUTKOWSKI, 2002, 2006; YE and JAYAWICKRAMA, 2008; FINLEY et al., 2009). In our study, all models that included a tensor product of B-splines (spatial model) had a smaller DIC (i.e., better fits) than non-spatial (Table 2), showing the benefits of including a random spatial process in the linear mixed model for the observed data. Neverthe- less, the average DIC reduction due to spatial effects captured by the B-splines was 404.4 and 168.6 for the ' $\mathrm{S}$ in $\mathrm{R}$ ' and IB designs, respectively. That means, overall the a priori IB design was more effective in accommodating the environmental spatial heterogeneity than the ' $\mathrm{S}$ in $\mathrm{R}$ ' design. For example, the average reduction (and increases of the precision) of $\hat{\sigma}_{e}^{2}$ were $13.9 \%(8.4 \%)$ and $18.0 \%(12.3 \%)$ for IB and 'S in R', respectively. Therefore, as expected, incomplete block designs were better than complete block designs in controlling the site variations (Fu et al., 1998; WiLliams and MATHESON, 1994).

\section{Spatial patterns}

Small- and large-scale variations in one or two dimensions together with small-scale variation were observed in the 10 western hemlock second-generation progeny trials. In general, large-scale continuous spatial variation in these trials would be due to factors such as gradual change in the topography, gradients in soil

Table 2. - Deviance Information Criterion (DIC, expressed as differences from the DIC for the non-spatial model), posterior means (Mean) and standard deviations (SD) of the additive genetic variance $\left(\hat{\sigma}_{a}^{2}\right)$, dominance genetic variance $\left(\hat{\sigma}_{d}^{2}=4 \times \hat{\sigma}_{f}^{2}\right)$, error variance $\left(\hat{\sigma}_{e}^{2}\right)$, individual narrow-sense heritability $\left(\hat{h}_{\mathrm{N}}^{2}\right)$, individual broad-sense heritability $\left(\hat{h}_{\mathrm{B}}^{2}\right)$, dominance to additive variance ratio $\left(\hat{\sigma}_{d}^{2} / \hat{\sigma}_{a}^{2}\right)$, replicates variances $\left(\hat{\sigma}_{r}^{2}\right)$ and incomplete block variance $\left(\hat{\sigma}_{s}^{2}\right)$ from the non-spatial (NonSP) and spatial (SP) single trial models.

\begin{tabular}{|c|c|c|c|c|c|c|c|c|c|c|c|c|c|c|c|c|c|c|}
\hline \multirow{2}{*}{$\begin{array}{l}\text { Sites } \\
\text { 'Local Dia }\end{array}$} & \multirow{2}{*}{$\begin{array}{l}\text { Model| } \\
\text { Illels' }\end{array}$} & \multirow[t]{2}{*}{ DIC } & \multicolumn{2}{|c|}{$\hat{\sigma}_{i i}^{2}$} & \multicolumn{2}{|c|}{$\hat{\sigma}^{2}$} & \multicolumn{2}{|c|}{$\hat{\sigma}^{2}$} & \multicolumn{2}{|c|}{$\hat{h}_{\mathrm{x}}^{2}$} & \multicolumn{2}{|c|}{$\hat{h_{\mathrm{b}}^{2}}$} & \multicolumn{2}{|c|}{$\hat{\sigma}_{d}^{2} / \hat{\sigma}_{a}^{2}$} & \multicolumn{2}{|c|}{$\hat{\sigma}_{r}^{2}$} & \multicolumn{2}{|c|}{$\hat{\sigma}_{s}^{2}$} \\
\hline & & & Mean & SD & Mean & SD & Mean & SD & Mean & SD & Mean & SD & Mean & SD & Mean & SD & Mean & SD \\
\hline \multirow[t]{2}{*}{ Jordan 2} & NonsP & & 887.2 & 234.5 & 505.7 & 191.3 & 20039.9 & 433.8 & 0.04 & 0.01 & 0.07 & 0.01 & 0.62 & 0.32 & 2608.0 & 740.7 & - & - \\
\hline & SP3O & 1132.29 & 896.8 & 241.0 & 492.8 & 210.7 & 15948.7 & 367.8 & 0.05 & 0.01 & 0.08 & 0.02 & 0.60 & 0.35 & - & - & - & - \\
\hline \multirow[t]{2}{*}{ Kiyu } & NonsP & & 624.6 & 203.2 & 783.2 & 268.6 & 21110.6 & 514.5 & 0.03 & 0.01 & 0.06 & 0.02 & 1.40 & 0.71 & 3258.5 & 926.3 & - & - \\
\hline & SP30 & 297.41 & 554.8 & 192.3 & 766.3 & 278.7 & 14248.4 & 383.2 & 0.04 & 0.01 & 0.09 & 0.02 & 1.59 & 0.94 & - & - & - & - \\
\hline Jordan 3 & NonSP & & 799.2 & 236.3 & 558.8 & 220.4 & 19187.6 & 449.7 & 0.04 & 0.01 & 0.07 & 0.02 & 0.77 & 0.43 & 3118.9 & 891.0 & - & - \\
\hline \multirow[t]{2}{*}{ Rupert 1} & NonsP & & 1721.6 & 413.9 & 62.7 & 34.9 & 27093.3 & 655.0 & 0.06 & 0.01 & 0.06 & 0.01 & 0.04 & 0.02 & 5012.7 & 1485.0 & - & - \\
\hline & SP10 & 321.25 & 1812.2 & 440.5 & 17.4 & 10.1 & 24688.5 & 618.2 & 0.07 & 0.02 & 0.07 & 0.02 & 0.01 & 0.01 & - & - & - & - \\
\hline \multirow[t]{2}{*}{ Russell } & NonsP & & 543.5 & 161.6 & 0.0 & 0.0 & 14340.2 & 529.2 & 0.04 & 0.01 & 0.04 & 0.01 & 0.00 & 0.00 & 1682.2 & 615.5 & - & - \\
\hline & SP30 & 394.46 & 528.0 & 192.6 & 0.0 & 0.0 & 11030.6 & 453.5 & 0.05 & 0.02 & 0.05 & 0.02 & 0.00 & 0.00 & - & - & - & - \\
\hline \multicolumn{3}{|c|}{ Humptulips NonSP } & 1174.2 & 286.4 & 448.4 & 160.9 & 18329.3 & 400.3 & 0.06 & 0.01 & 0.08 & 0.02 & 0.41 & 0.20 & 8154.9 & 2309.0 & - & - \\
\hline & SP10 & 28.86 & 1116.3 & 281.2 & 419.4 & 167.1 & 17204.2 & 383.5 & 0.06 & 0.02 & 0.08 & 0.02 & 0.41 & 0.22 & - & - & $=$ & $=$ \\
\hline \multicolumn{19}{|c|}{ 'Elites Crosses' } \\
\hline \multirow[t]{2}{*}{ Klanawa } & NonsP & & 1225.2 & 376.7 & 0.0 & 0.0 & 19542.5 & 569.1 & 0.06 & 0.02 & 0.06 & 0.02 & 0.00 & 0.00 & 4816.7 & 1198.0 & 2786.9 & 1011.0 \\
\hline & SP30 & 69.09 & 1235.5 & 368.6 & 0.0 & 0.0 & 14903.2 & 478.2 & 0.08 & 0.02 & 0.08 & 0.02 & 0.00 & 0,00 & - & - & - & - \\
\hline \multirow[t]{2}{*}{ Stove } & NonsP & & 1834.8 & 518.7 & 1143.5 & 360.8 & 16769.1 & 495.5 & 0.10 & 0.03 & 0.16 & 0.03 & 0.67 & 0.30 & 1237.1 & 323.9 & 952.5 & 345.7 \\
\hline & $5 P 30$ & 458.07 & 1883.2 & 528.8 & 1090.1 & 340.7 & 15043.8 & 480.0 & 0.11 & 0.03 & 0.17 & 0.03 & 0.62 & 0.27 & - & - & - & - \\
\hline \multirow[t]{2}{*}{ Tlupana } & NonsP & & 1710.6 & 494.4 & 308.4 & 136.3 & 20453.2 & 581.0 & 0.08 & 0.02 & 0.09 & 0.02 & 0.20 & 0.11 & 4121.4 & 1015.0 & 2783.7 & 1007.0 \\
\hline & SP10 & 40.11 & 1665.6 & 478.8 & 330.9 & 145.1 & 18900.7 & 545.1 & 0.08 & 0.02 & 0.10 & 0.02 & 0.22 & 0.12 & - & - & - & - \\
\hline \multirow[t]{2}{*}{ Michelsen } & NonSP & & 841.1 & 265.7 & 812.6 & 294.5 & 15896.1 & 416.3 & 0.05 & 0.02 & 0.10 & 0.02 & 1.07 & 0.55 & 1237.1 & 322.2 & 943.8 & 342.6 \\
\hline & SP10 & 107,12 & 914.0 & 274.9 & 960.1 & 297.8 & 15370.1 & 408.4 & 0.06 & 0.02 & 0.11 & 0.02 & 1.15 & 0.52 & - & - & - & - \\
\hline
\end{tabular}

Note: ${ }^{a}$ Model NonSP: non-spatial model with replicates and incomplete block effects.

Model SP10: P-splines with 10 knots for rows and 10 knots for columns.

Model SP30: P-splines with 30 knots for rows and 30 knots for columns. 
attributes (nutrients, moisture and drainage), and anthropologic factors such as road building further affecting drainages patterns and soil compaction after logging activities. Meanwhile, small-scale variation would largely be due to: variable micro-site soil moisture, wet and dry pockets, variation in drainage, variable soil depth, from the presence of rocks and root rots of old trees, and uneven distribution of organic matter and nutrients which is particularly important for western hemlock. Three examples of the typical spatial patterns of the residuals found in these progeny trials, and the spatial effects estimated, are displayed in Figure 1. Figure $1 b$ illustrates the estimated smoothest surface for the mixed model with best fits (i.e., smaller DIC) for the small-scale spatial variation in Kiyu: $30 \times 30$ knots (SP30), and for the small- and distinct large-scale spatial variability in one dimension in Humptulips, and two dimensions in Tlupana: $10 \times 10$ knots (SP10). Additionally, the estimated surface with the spatial models shows that the degree of smoothness decreases with the increase in the number of knots from 10 to 30 to allow for more refined fits of the environmental variation. Visual comparison between the best estimated smoother surfaces of spatial models (Figure 1b) and the corresponding spatial patterns of the residuals (Figure 1a) highlights only slight differences.

The number of knots affects the amount of smoothing applied to the data by controlling the number of piecewise fits. In trials with predominately large-scale variation in two dimensions (Rupert 1 and Tuplana) together with some smaller scale variation, the smaller number of knots studied (i.e., $10 \times 10$ knots for row and column) lead to a smooth surface that is flexible enough to capture the main (predominate) large-scale continuous spatial variation as well as the less significant micro-site variability in the data (e.g., Tuplana Figure 1b). In the other extreme, in trials with predominance of smallscale spatial variation (e.g., Kiyu, Jordan 3, Klanawa and Russell) the use of a large number of knots (i.e., $30 \times 30$ knots for row and column) allowed for more flexibility in fitting peaks and valleys and therefore better account for the patchy micro-site patterns (e.g., Kiyu, Figure $1 b)$. In trials with large-scale variation in one dimension (e.g., Humptulips, Michelsen, Jordan 2 and Stove), together with small-scale variation, depending on the predominance of either small-scale or large-scale variation in one direc- tion, the models with $10 \times 10(\mathrm{SP} 10)$ or $30 \times 30$ knots (SP30) yielded the best fit. For example, Humptulips showed an environmental variation visually distinct large-scale environmental variation in one directions but with a less significant small-scale variation (Figure $1 a$ ) and 10 knots for row and column were enough to model these patterns of spatial variability (Figure 1b).

\section{Effect of the spatial single trial analysis on genetic parameters}

Small- and large-scale spatial variations are commonly observed in forest genetic trials, either alone or in combination with each other (e.g., Fu et al., 1999; Costa e SILva et al., 2001; HAMANN et al., 2002; DUTKOWSKI et al., 2006; YE and JAYAWICKRAMA, 2008). Unaccounted spatial variability in forest genetic trials can lead to bias in estimates of genetic parameters and predicted breeding values (MAGNUSSEN, 1993, 1994); a bias which diminishes accuracy of selection. In the current research, we fit a twodimensional surface using a tensor product of cubic B-spline basis functions with equal number of knots for rows and columns in an individual-tree mixed model (CAPPA and CANTET, 2007), to remove small-scale spatial variation and large-scale variations in one or two dimension together with small-scale on 10 second-generation progeny trials of western hemlock. Our results showed that the fit of smoothed surfaces produced a reduction of $\hat{\sigma}_{e}^{2}$ across the 10 trials, ranging from 3.3 to $32.5 \%$, and an increment in its precision (i.e., lower standard deviations) by 1.9 to $25.5 \%$ (Table 2). These reductions confirm that there are spatial variations that are not adequately accounted for by the $a$ priori design effects. Moreover, most of the high posterior density intervals for $\hat{\sigma}_{e}^{2}$ were disjoint between the non-spatial and spatial models (results not shown). In a progeny trial of Eucalyptus globulus ssp. globulus, CAPPA and CANTET (2007) by means of the same method applied in this study, with cubic B-splines and equal number of knots for row and column, reported a $50 \%$ reduction in the error variance from the model with an apriori randomized complete block design. After adjusting a separable autoregressive $(A R(1) \times A R(1))$ error structure, several studies showed a reduction in the $\hat{\sigma}_{e}^{2}$ (e.g. CosTA e Silva et al., 2001; DutKowski et al., 2006; YE and JAYAWICKRAMA, 2008). However, DUTKOWSKI et al. (2002) showed only slight changes of the error variances in the five progeny trials they 
analyzed. Additionally, SAENZ-Romero (2001) reduced the residual error by $42 \%$ using quadratic polynomials for rows and columns and correlated errors, whereas no changes were reported by HAMANN et al. (2002) using Kriging. The fit of a smoothed surface to the 10 progeny tests of western hemlock, instead of the $a$ priori ' $\mathrm{S}$ in $\mathrm{R}$ ' and IB designs, showed a small but inconsistent effect on the estimated additive genetic variance $\left(\hat{\sigma}_{a}^{2}\right.$, Table 2), with $\hat{\sigma}_{a}^{2}$ both decreasing and increasing in value from -11.2 to $9.3 \%$. Different a posteriori spatial approaches in other forest genetic trials and species have also shown variable affects on $\hat{\sigma}_{a}^{2}$. Inconsistent effects are typically seen when the data model includes a spatial autoregressive correlated error terms (e.g. YE and JAYAWICKRAMA, 2008; DUTKOWSKI et al., 2006, 2002; Costa e Silva, 2001). However, Joyce et al. (2002) reported a consistent decrease in the in a farm-field test of black spruce, using a two-step approach. ZAS (2006) using an iterative Kriging method found a consistent increase in the genetic variance in four large Pinus pinaster Ait. progeny trials. In three genetics trials of red alder (Alnus rubra Bong.), HAMANN et al. (2002), who removed the spatial variability by means of single Kriging, reported an increase in the genetic variance compared to classical analysis. Other studies have also reported an increase in $\hat{\sigma}_{a}^{2}$ (KUSNANDAR and GALWEY, 2000; ANEKONDA and LIBBY, 1996).

Estimated of $h_{\mathrm{N}}^{2}$ for the univariate models that fitted the best two-dimensional surface were consistently higher than those estimated with a non-spatial model. Although the average increase in heritability was only $\sim 0.01$, the increment ranged from 1.7 to $29.3 \%$, with an average of $19.3 \%$ which is quite significant for such a low heritability trait. In contrast, estimated of $h_{\mathrm{N}}^{2}$ from a earlier study using a multienvironment non-spatial and spatial models (see Table 3 in CAPPA et al., 2012) showed inconsistent changes between the series, increasing (to a maximum of $66.7 \%$ in the $\mathrm{LD}$ series) or decreasing (less than $11.1 \%$ in the ED series).

The Spearman-rank correlation between predicted breeding values from the non-spatial models and the best spatial models across the 10 trials were on average $0.960,0.972$ and 0.974 for families, parents and offspring, respectively, indicating that there was very little re-ranking among families, parents and the progenies. Additionally, in keeping with the general reduc- tions in $\hat{\sigma}_{a}^{2}$, the average accuracy of breeding values from parents and offspring estimated with the best spatial model were higher than the corresponding values estimated with the non-spatial $a$ priori ' $\mathrm{S}$ in $\mathrm{R}$ ' and IB designs (averaging $4.5 \%$ for families and $2.7 \%$ for parent and offspring), which are in agreement with several studies that compared spatial models with different a priori designs (YE and JAYAWICKRAMA, 2008; ZAS, 2006; DUTKOWSKI et al., 2006, 2002; Costa e Silva et al., 2001). A substantial fraction of the gain in accuracy is due to the fact that not all environmental spatial variability is accounted for the design features, variation that would otherwise go to the error variance.

In spite of the fact the best fitting spatial models had large reductions with respect to DIC (Table 2), the relative genetic gain improvements in the LD series were less than $5.12 \%$ for parents and $3.71 \%$ for offspring, when the top $20 \%$ and $5 \%$ of the parents and offspring are selected. Due to the small number of parents (30) in the E series trials, not surprisingly there was effectively no additional parent level gain, but there was an offspring gain for the use of the spatial analyses. Even with small absolute increases in $h_{\mathrm{N}}^{2}$ (i.e., 0.02), and average genetic gain improvements of 1.47 and $1.53 \%$ for parents and offspring, respectively, selection decisions based on inference with a spatial process model would differ from those based on a conventional design-consistent inference and this has an important implications in particularly for the LD series. Modest changes in the predicted genetic gain with spatial adjustment were also reported by $\mathrm{YE}$ and JAYAWICKRAMA (2008).

\section{Heritabilities estimates and ratio of dominance to additive genetic variance}

Estimated of $h_{\mathrm{N}}^{2}$ and $h_{\mathrm{B}}^{2}$ for height from the single site analyses were low, with the average estimates across the six LD series trials being 0.05 and 0.07 , respectively; and 0.08 and 0.12 for the respective values estimates across the four ED series trials (Table 2). In an earlier study, CAPPA et al. (2012) showed that estimates of $h_{\mathrm{N}}^{2}$ and $h_{\mathrm{B}}^{2}$ at each site from a novel spatial MET model were still low, with the average estimates across the five LD series trials being 0.06 and 0.09 , respectively. Meanwhile, the corresponding values estimated for the average of 
the three ED series trials were 0.08 and 0.11 (see Table 3 in CAPPA et al., 2012). These estimates were lower (an average of $\sim 0.08$ ) than that found in 213 open-pollinated families of western hemlock for Foster and Lester (1982) (their values ranged from 0.09 to 0.23 ) across four test sites planted in OR and WA. However, JAYAWICKRAMA (2003; see Table 2) reviewed estimates of western hemlock individual-tree heritabilities, and estimated $h_{\mathrm{B}}^{2}$ for height growth from other sets of open-pollinated trials planted in OR and WA, and these were also usually less than 0.1 (typically around 0.06 to 0.07 ). Although, the estimated of $h_{\mathrm{B}}^{2}$ tend to also be lower than comparable estimates for Douglasfir in the region (e.g. YANCHUK, 1996) and for other temperate conifers (e.g. Wu and MATHESON, 2004), it appears western hemlock simply has low heritiabilities for early height growth.

The relative importance of additive to nonadditive genetic variance plays a vital role in practical tree breeding: choice of breeding and deployment population strategies, prediction of response to selection and evaluation of breeding systems (WU and MATHESON, 2004). The estimated of $\sigma_{d}^{2}$ relative to $\sigma_{a}^{2}\left(\sigma_{d}^{2} / \sigma_{a}^{2}\right)$ for height at the age of 10 years varied among the ten sites (from 0.00 to 1.59 ; Table 2), which suggested that capturing of the dominance variation for height in western hemlock would require aiming to some specific crosses to specific sites. Until now, little has been published on dominance variance in western hemlock and the reliability of the estimates are typically limited by there being a relatively small number of genetic entries (i.e. mating design with few full-sib families) included in the analysis. The estimates of $\sigma_{d}^{2} / \sigma_{a}^{2}$ also were variable among eight western hemlock trials studied by CAPPA et al. (2012) and using a spatial MET model (from 0.00 to 1.17; see Table 3 in CAPPA et al., 2012). Such variable estimates of the $\sigma_{d}^{2} / \sigma_{a}^{2}$ ratio across sites were also observed in other Pinus species. For example, in radiata pine estimates of the variance ratio of specific combining ability to general combining in tree diameter, ranged from $20 \%$ to $1,035 \%$ across $106 \times 6$ half-diallel mating experiments planted at ten sites across Australia (Wu and MAtheson, 2004). In Pinus sylvestris, ZHELEV et al. (2003) estimated the ratio of non-additive to additive genetic variance in height growth at the age of 12 and 16 years from 144 full-sib families $(12 \times 12$ factorial cross) located at four test sites, and reported that varied from $1.0 \%$ to $71.2 \%$. WALDMANN et al. (2008), in a recent review in pines, concluded that there seems to be no general trend about the level of dominance compared to additive variance, but it often seems as if at least some dominance is present in growth traits.

\section{Additive genetic correlations between sites from the spatial MET analysis}

Multi-environment forest genetics trials allowed studying the magnitude and importance of the genotype by environment interactions. Rank-change interaction is reflected in departures of the additive genetic correlations between sites $j$ and $j^{\prime}\left(r_{a j j^{\prime}}\right)$ from the perfect correlation (i.e. $r_{a j j}=+1$ ). CAPPA et al. (2012) showed that average estimates for $r_{a j j}$, among sites from the spatial MET analysis were relatively high for the $\mathrm{LD}$ (0.75) and ED (0.88) series, indicating that the additive by environment interaction was low in this full-sib material (see Table 4 in CAPPA et al., 2012). However, high posterior density intervals do not include $r_{a j j}=+1$; therefore, some rank changes between sites could be possible. Foster and LESTER (1983) showed no significant family by site interaction on fifth-year height in their study of western hemlock (the four sites varied from $45^{\circ} 30$ (Tillamook, OR) to $48^{\circ} 15$ (Clallam Bay, WA) latitude north and altitudes from 110 to 440 meters). POLlARD and PorTlOCK (1986) found similar results for height growth in four provenance test sites located in Vancouver Island (BC, from $48^{\circ} 55$ to $50^{\circ} 37$ of latitude north), with no interaction provenance by site.

A slight trend was apparent with more geographically close sites having higher genetic correlations (see Figure 1 and Table 4 in CAPPA et al., 2012). For example, Humptulips (WA, $47^{\circ} 13$ '52") had significantly higher $r_{a j j}$ 'values with Jordan 2 (Vancouver Island, 48 25'16"; 0.88 ) and 3 (Vancouver Island, $48^{\circ} 24^{\prime} 44^{\prime \prime} ; 0.89$ ) than with Kiyu (Vancouver Island, 50 05’07'; 0.73 ) and the distant Rupert 1 site (Vancouver Island, 50³4'21"; 0.61). Moreover, there was no overlap in the $95 \%$ HPD of the $r_{a j j}$ ' between Humptulips and the most southern BC: Jordan 2 and 3 trials and the north BC: Kiyu and Rupert 1 trials. Although only eight second-generation full-sib progeny trials were included in the spatial MET analysis reported by CAPPA et al. (2012), and thus only thirteen $r_{a j j}$, between 
pairs of sites from the multi-environment spatial model may be estimated, linear regressions of $r_{a j j}$, on absolute differences in latitude, longitude and altitude between pairs of trials, were examined. In spite of the maximum latitudinal and longitudinal difference among trials in both series being $3.4^{\circ}$ and $3.8^{\circ}$, respectively (Table 1 ), the slope of both absolute difference in latitude (i.e. north-south) and longitude (i.e. east-west) were statistically significant $(p<0.05)$. However, the adjusted $\mathrm{R}^{2}$ were low to moderate (difference in latitude $=0.34$ and difference in longitude $=0.47$, Figure 2), which suggests that the geographic distance (i.e. latitude and longitude) have a small but significant negative effect on genetic correlation between sites at age-10 height for western hemlock in this set of trials. The latitudinal and longitudinal differences were highly associated with differences in the annual mean temperature (Pearson correlation equal to 0.93 and 0.75 , respectively; maximum temperature difference 2.4 degree Celsius), and thus showing a latitudinal (and longitudinal) temperature gradient. Therefore the slightly lower genetic correlations between the northern and the most southern sites are likely the result of temperature differences attributable to latitudinal and longitudinal effects impacting on the performance of some genotypes. This would require more detailed analyses of which may be the more interactive families, on which particular sites, but this is a topic of future research. A latitudinal trend (i.e. north-south trend) was reported in a seedling study of three open-pollinated families from each of 21 western hemlock different provenances from $38^{\circ} 38$ in California to $58^{\circ} 23$ in Alaska, for cold hardiness, survival (KUSER and CHING, 1980) and seedling growth (Kuser and ChIng, 1981). Nevertheless, as pointed out by KING (1990), this clinal trend is not maintained when the more extreme provenances of high and low latitudes are removed.

Linear regressions of $r_{a j j}$, on absolute difference in altitude, showed no statistically significant effect ( $p>0.05$; Figure 2$)$; which suggests that the altitudinal differences of these trials did not have a noticeable effect on $r_{a j j}$, in western hemlock. However, KING (1990) based on the results of the four best heritability sites on one of three series of tests of open-pollinated progeny trials of western hemlock, observed that there was more interaction among family means between low and higher elevation sites (i.e. from 150 to 1100 meter of altitude). The non-significant difference among $r_{a j j}$, and the
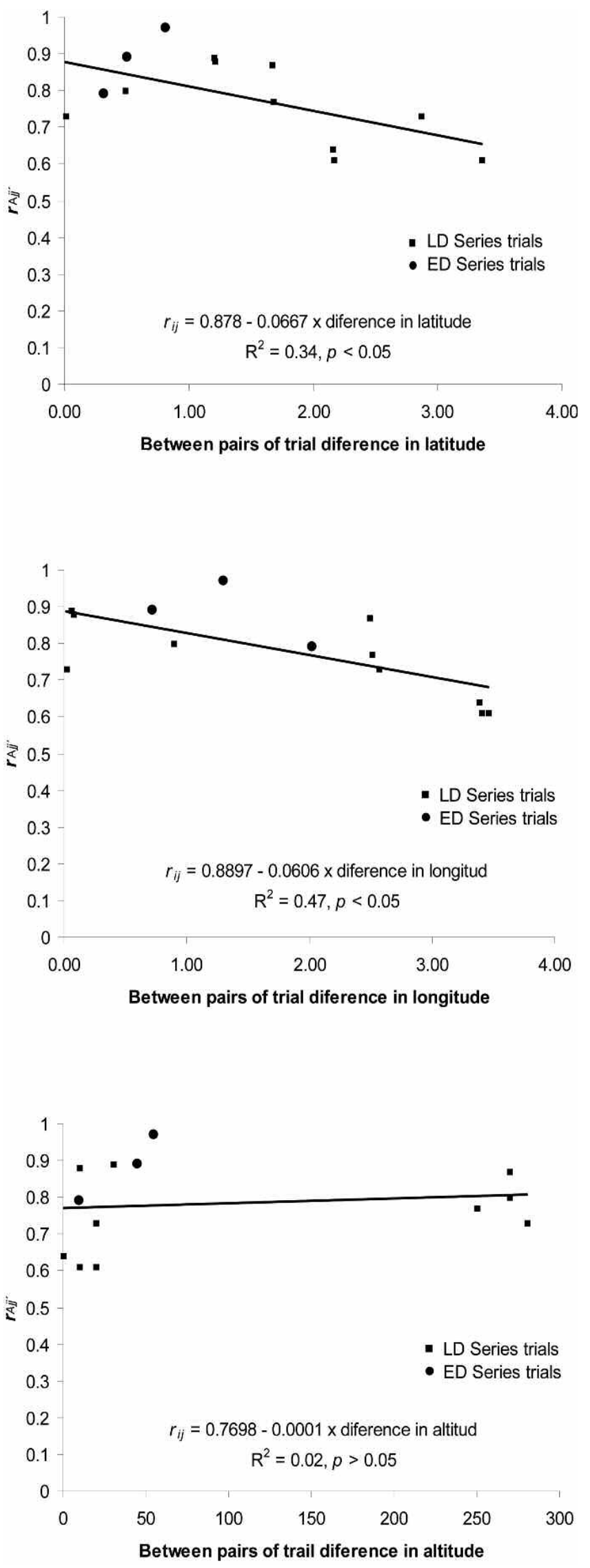

Figure 2. - Regression of additive genetic correlations $\left(r_{a j j},\right)$ on between site absolute difference in latitude (a), longitude (b) and altitude (c) for the 13 western hemlock full-sib progeny trial pairs. 
absolute difference in altitude in this study may be because these trials were on sites with a small elevational range (i.e. from 45 to 590 meters).

\section{Conclusion and implications for tree improvement in western hemlock}

We found that the mixed model with the smoothing surface will allow us to model different and complex patterns of spatial variation in the 10 large progeny trials of western hemlock. The mixed model enable us to account for smalland/or the large-scale environmental variation, simply by increasing of the number of knots, and the retention design effects or the addition of fixed or random classification variables were not needed.

Height growth trait appears to be heritable but under a low degree of genetic control with individual narrow-sense heritabilities around 0.08 . This outcome was expected and while family selection would be satisfactory for selecting seed orchard candidates, within family (forward) selections would have to be assessed in polycross tests before inclusion in seed orchards. Second generation trials established in 2005 used clonal replication (rooted cuttings) to address the problem of poor accuracy of individual tree breeding value predictions. The importance of dominance variance varied among the ten sites, which suggested that capturing dominance variation for height in western hemlock would require allocating to some specific crosses on specific sites. However, given the reluctance on the part of the forest industry to invest in the silviculture of western hemlock, this approach is unlikely to be adopted.

Additive genetic correlations estimates between sites obtained by CAPPA et al. (2012) showed a slight trend with the geographic distance (i.e. latitude and longitude), probably associated with differences in the annual mean temperature. However, and despite these environmental differences across trials, the height trait on the different sites can be considered the same trait, since there were weak additive by environmental interactions across of the eight trials. Clearly the current seed zone in which all the trials are located provides acceptable administrative bounds. Given the wide range of origins of trees tested, a reassessment of a subset of tests at age 15 or 20 years is advisable.

\section{Acknowledgements}

This research was supported by funds from British Columbia of Forest and Range, and support to the senior author as a Post-doctoral Fellow at the University of British Columbia.

\section{References}

ANeKondA, T. S. and W. J. LiBBy (1996): Effectiveness of nearest neighbor data adjustment in a clonal test of Redwood. Silvae Genet. 45(1): $46-51$.

Cantet, R. J. C., A. N. Birchmeier, A. W. Canaza CAYO and C. Fiorett (2005): Semiparametric animal models via penalized splines as alternatives to models with contemporary groups. J. Anim. Sci. 83: 2482-2494.

CAPPA, E. P. and R. J. C. CANTET (2007): Bayesian estimation of a surface to account for a spatial trend using penalized splines in an individual-tree mixed model. Can. J. For. Res. 37: 2677-2688.

CAPPA, E.P., A. D. YANChUK and C. V. CARTwRight (2012): Bayesian inference for multi-environment spatial individual-tree models with additive and full-sib family genetic effects for large forest genetic trials. Annals of Forest Science 69: 627-640. DOI: 10.1007/s13595-011-0179-7.

Costa E Silva, J., G. W. Dutkowski and A. R. GILMOUR (2001): Analysis of early tree height in forest genetic trials is enhanced by including a spatially correlated residual. Can. J. For. Res. 31: 1887-1893.

DE Boor, C. (1993): B(asic)-spline basics. Fundamental Developments of Computer-Aided Geometric Modeling. L. Piegl, ed. Academic Press, San Diego, CA.

Durban, M., I. CuRrie and R. Kempton (2001): Adjusting for fertility and competition in variety trials. J. Agric. Sci. (Camb.) 136: 129-140.

Dutkowski, G. W., J. Costa e Silva, A. R. Gilmour and G. A. Lopez (2002): Spatial analysis methods for forest genetic trials. Can. J. For. Res. 32: 2201-2214.

Dutkowski, G. W., J. Costa E Silva, A. R. Gilmour, H. Wellendorf and A. Aguiar (2006): Spatial analysis enhances modeling of a wide variety of traits in forest genetic trials. Can. J. For. Res. 36: 1851-1870.

Finley, A. O., S. BanerJee, P. Waldmann and T. ERICSSON (2009): Hierarchical spatial modeling of additive and dominance genetic variance for large spatial trial data sets. Biometrics 65: $441-451$.

Foster, G. S. and D. T. Lester (1983): Fifth-year height variation in western hemlock open pollinated families growing on four test sites. Can. J. For. Res. 13: 251-256.

Fu, Y. B., A. D. Yanchuk and G. NAmkoong (1999): Spatial patterns of tree height variations in 
a series of Douglas-fir progeny trials: implications for genetic testing. Can. J. For. Res. 29: 714-723.

Fu, Y. B., G. P. Y. Clarke, G. NAmkoong and A. D. YANCHUK (1998): Incomplete block designs for genetic testing: statistical efficiencies of estimating family means. Can. J. For. Res. 28: 977-986.

Gilmour, A. R., B. J. Gogel, B. R. Cullis and R. ThOMPson (2006): ASReml User Guide Release 2.0 VSN International Ltd, Hemel Hempstead, HP1 1ES, UK.

Green, P. J. and B. W. Silverman (1994): Nonparametric Regression and Generalized Linear Model. Chapman \& Hall, London, UK.

Grondona, M. O., J. Crossa, P. N. Fox and W. H. PFEIFFER (1996): Analysis of variety yield trials using 2-dimensional separable ARIMA processes. Biometrics 52: 763-770.

Hamann, A., M. Koshy and G. NAmkoong (2002): Improving precision of breeding values by removing spatially autocorrelated variation in forestry field experiments. Silvae Genet. 51: 210-215.

HaRville, D. A. (1997): Matrix algebra from a statistician's perspective. Springer-Verlag. New York.

Henderson, C. R. (1984): Applications of Linear Models in Animal Breeding. Canada, University of Guelph, Guelph, Ont.

Hyndman, R. J., M. L. King, I. Pitrun and B. Billah (2005): Local lineal forecasts using cubic smoothing splines. Aust. N. Z. J. Stat. 47: 87-99.

JAYAWICKRAMA, K. J. S. (2003): Genetic improvement and deployment of western hemlock in Oregon and Washington: Review and Future Prospects. Silvae Genet. 52(1): 26-36.

Joyce, D., R. Ford and Y. B. Fu (2002): Spatial patterns of tree height variations in a black spruce farm-field progeny test and neighbors-adjusted estimations of genetic parameters. Silvae Genet. 51: 13-18.

KING, J. N. (1990): The significance of geographic variation patterns for western hemlock genetic improvement. Technical Report, B.C. Ministry of Forests Research Branch, 12 p.

Kuser, J. E. and K. K. CHING (1981): Provenance variation in seed weight, cotyledon number, and growth rate of western hemlock seedlings. Forest Science, 26: 463-470.

Kuser, J. E. and K. K. CHING (1981): Provenance variation in seed weight, cotyledon number, and growth rate of western hemlock seedlings. Can. J. For. Res. 11: 662-670.

Kusnandar, D. and N. Galwey (2000): A proposed method for estimation of genetic parameters on forest trees without raising progeny: critical evaluation and refinement. Silvae Genet. 49: 15-21.

Magnussen, S. (1993): Bias in genetic variance estimates due to spatial autocorrelation. Theor. Appl. Genet. 86: 349-355.

Magnussen , S. (1994): A method to adjust simultaneously for statial microsite and competition effects. Can. J. For. Res. 24: 985-995.
PoJAR, J. and A. MACKInNON (1994): Plants of the Pacific Northwest Coast, Washington, Oregon, British Columbia \& Alaska. Lone Pine Publishing, Vancouver, British Columbia.

Pollard, D. F. W. and F. T. Portlock (1986): Intraspecific variation in stem growth of western hemlock. Can. J. For. Res. 16: 149-151.

R Development Core Team (2011): R: A language and environment for statistical computing. $\mathrm{R}$ Foundation for Statistical Computing, Vienna, Austria. ISBN 3-900051-07-0, URL http://www. R-project.org/.

RupPert, D., M. P. WAND and R. J. CARROLL (2003): Semiparametric Regression. Cambridge Univ. Press, Cambridge, UK.

Saenz-Romero, C., E. V. Nordheim, R. P. Guries and P. M. CRUMP (2001): A Case Study of a Provenance/Progeny Test Using Trend Analysis with Correlated Errors and SAS PROC MIXED. Silvae Genet. 50: 127-135.

Schutz, W. M. and C. C. Cockerham (1966): The Effect of Field Blocking on Gain from Selection. Biometrics 22(4): 843-863.

Silverman, B. (1986): Density Estimation for Statistics and Data Analysis, Chapman and Hall, London.

Smith, B. J. (2003): Bayesian Output Analysis Program (BOA) version 1.0 user's manual. Available from http://www.public-health.uiowa.edu/boa/ Home.html.

Spiegelhalter, D. J., N. G. Best, B. P. Carlin and A. VAN DER LINDE (2002): Bayesian measures of model complexity and fit (with discussion). Journal of the Royal Statistical Society Series B 64: 583-639.

Waldmann, P., J. Hallander, F. Hoti and M. J. SILLANPÄÄ (2008): Efficient MCMC implementation of Bayesian analysis of additive and dominance genetic variances in non-inbred pedigrees. Genetics 179: 1101-1112.

WEBBER, J. E. (2000): Western hemlock: a manual for tree improvement seed production. Res. Br., B. C. Min. For., Victoria, B.C.Work Pap. $44 / 2000$.

White, T. L. (1996): Genetic parameter estimates and breeding value predictions: issues and implications in tree improvement programs. In: Dieters, M. J., Matheson, A. C., Nikles, D. G., Harwood, C. E., Walker, S. M. (eds) Proceedings of the QFRI-IUFRO Conference Tree Improvement for Sustainable Tropical Forestry. Caloundra, Queensland, Australia, pp 110-117.

Williams, E. R. and A. C. Matheson (1994): Experimental Design and Analysis for use in Tree Improvement. CSIRO, Melbourne, Australia.

Wu, H. X. and A. C. Matheson (2004): General and specific combining ability from artial diallels of radiata pine: implications for utility of SCA in breeding and deployment populations. Theor. Appl. Genet. 108: 1503-1512. 
YANCHUK, A. (1996): General and specific combining ability from disconnected partial diallels of coastal Douglas-fir. Silvae Genet. 45: 37-45.

YE, T. Z. and K. J. S. JAYAWICKRAMA (2008): Efficiency of using spatial analysis in firest-generation coastal Douglas-fir progeny tests in the US Pacific Northwest. Tree Genetics and Genomes 4: 677-692.
ZAS, R. (2006): Iterative kriging for removing spatial autocorrelation in analysis of forest genetic trials. Tree Genetics and Genomes 2: 177-185.

Zhelev, P., I. Ekberg, G. Eriksson and L. Norell (2003): Genotype environment interactions in four full-sib progeny trials of Pinus sylvestris (L.) with varying site indices. Forest Genetics 10: 93-102.

\title{
Near rotation-length performance of selected hybrid larch in Central Maine, U.S.A.
}

\author{
By M. S. Greenwood ${ }^{1)}$, B. E. Roth ${ }^{\left.1,{ }^{*}\right)}$, D. MAASs $^{2)}$ and L. C. IRLAND ${ }^{1)}$
}

(Received $7^{\text {th }}$ May 2015)

\begin{abstract}
Twenty-two year measurements of a test of inter- and intraspecific larch hybrids among European (E), Japanese (J) and tamarack (T) parents growing in central Maine reveal significant hybrid vigor, especially among crosses involving $J$ and $\mathrm{E}$ parents. The mean heights and diameters of all the interspecific crosses between $\mathrm{J}$ and $\mathrm{E}$ parents exceeded those of intraspecific crosses among either of the parents. The mean height after 22 years for all 17 $\mathrm{JxE}$ and ExJ crosses was $19.2 \mathrm{~m}$ (63 feet), which compares favorably with heights of loblolly pine plantations at age 25 growing in the southeastern USA, where site index ranged from $12.2 \mathrm{~m}$ to $24.4 \mathrm{~m}$ (40 and 80 feet respectively). In addition the mean height of these larch crosses was $30 \%$ greater than that of a control hybrid seed lot of German origin. Crosses between $\mathrm{E}$ and $\mathrm{T}$ parents also performed well, but exhibited relatively poor form, and seed set was very low. Seed set and viability for crosses between $\mathrm{J}$ and $\mathrm{E}$ were as good as

1) School of Forest Resources, University of Maine, 5755 Nutting Hall, Orono ME 04469-5755, USA.

2) 5 Wildwood Circle, Portland, ME 04103, USA.

*) Corresponding author: BRIAN E. ROTH.

Phone (207) 581-2861. E-Mail: brian.roth@maine.edu
\end{abstract}

intraspecific parental crosses. Therefore propagation of hybrid larch crosses via controlled pollination and rooted cuttings is feasible, and the potential benefits of larch plantations for Maine's forest economy are briefly discussed.

Key Words: Hybrid larch, hybrid vigor, heterobeltiosis, Japanese larch, European larch, tamarack

\section{Introduction}

Reports of naturally occurring larch hybrids between European (Larix decidua Mill.) and Japanese larch (L. kaempferi (Lamb) Carriere) exhibiting exceptional growth followed the introduction of Japanese larch into European arboretums in 1861 (SANDER and LAANELAID, 2007). Since then, there has been considerable interest in realizing the potential of larch hybrids in France, Sweden, Quebec, the People's Republic of China and throughout US as a rapidly growing plantation species (PÂQUES, 1989; Perron, 2008; Eco et al., 2004). Over the last 30 years, plantations of an open-pollinated half-sib $\mathrm{E} \times \mathrm{J}$ family from a German seed orchard (LANGNER and SCHNECK, 1998) have been established in Maine, Nova Scotia, the Lake States and the state of Oregon. In Maine 